\title{
Preparation, toxicity reduction and radiation therapy application of gold nanorods
}

Lina Xie ${ }^{1}$, Xujia Zhang ${ }^{2}$, Chengchao Chu ${ }^{3}$, Yingqi Dong ${ }^{2}$, Tianzi Zhang ${ }^{2}$, Xinyue Li ${ }^{1}$, Gang Liu ${ }^{4}$, Wen Cai ${ }^{*}$ and Suxia $\operatorname{Han}^{1 *}$

\begin{abstract}
Gold nanorods (GNRs) have a broad application prospect in biomedical fields because of their unique properties and controllable surface modification. The element aurum (Au) with high atomic number (high-Z) render GNRs ideal radiosensitive materials for radiation therapy and computed tomography (CT) imaging. Besides, GNRs have the capability of efficiently converting light energy to heat in the near-infrared (NIR) region for photothermal therapy. Although there are more and more researches on GNRs for radiation therapy, how to improve their biocompatibility and how to efficiently utilize them for radiation therapy should be further studied. This review will focuse on the research progress regarding the preparation and toxicity reduction of GNRs, as well as GNRs-mediated radiation therapy.
\end{abstract}

Keywords: Gold nanorods (GNRs), Preparation, Toxicity reduction, Radiation sensitization, Radiation therapy

\footnotetext{
*Correspondence: caiwen2016@xjtu.edu.cn; shan87@mail.xjtu.edu.cn

${ }^{1}$ Department of Radiation Oncology, The First Affiliated Hospital, Xi'an

Jiaotong University, Xi'an 710061, Shaanxi, China

${ }^{2}$ Institute of Medical Engineering, School of Basic Medical Sciences,

Health Science Center, Xi'an Jiaotong University, Xi'an 710061, Shaanxi,

China

Full list of author information is available at the end of the article
} to the material. If material is not included in the article's Creative Commons licence and your intended use is not permitted by statutory regulation or exceeds the permitted use, you will need to obtain permission directly from the copyright holder. To view a copy of this licence, visit http://creativecommons.org/licenses/by/4.0/. The Creative Commons Public Domain Dedication waiver (http://creativeco mmons.org/publicdomain/zero/1.0/) applies to the data made available in this article, unless otherwise stated in a credit line to the data. 


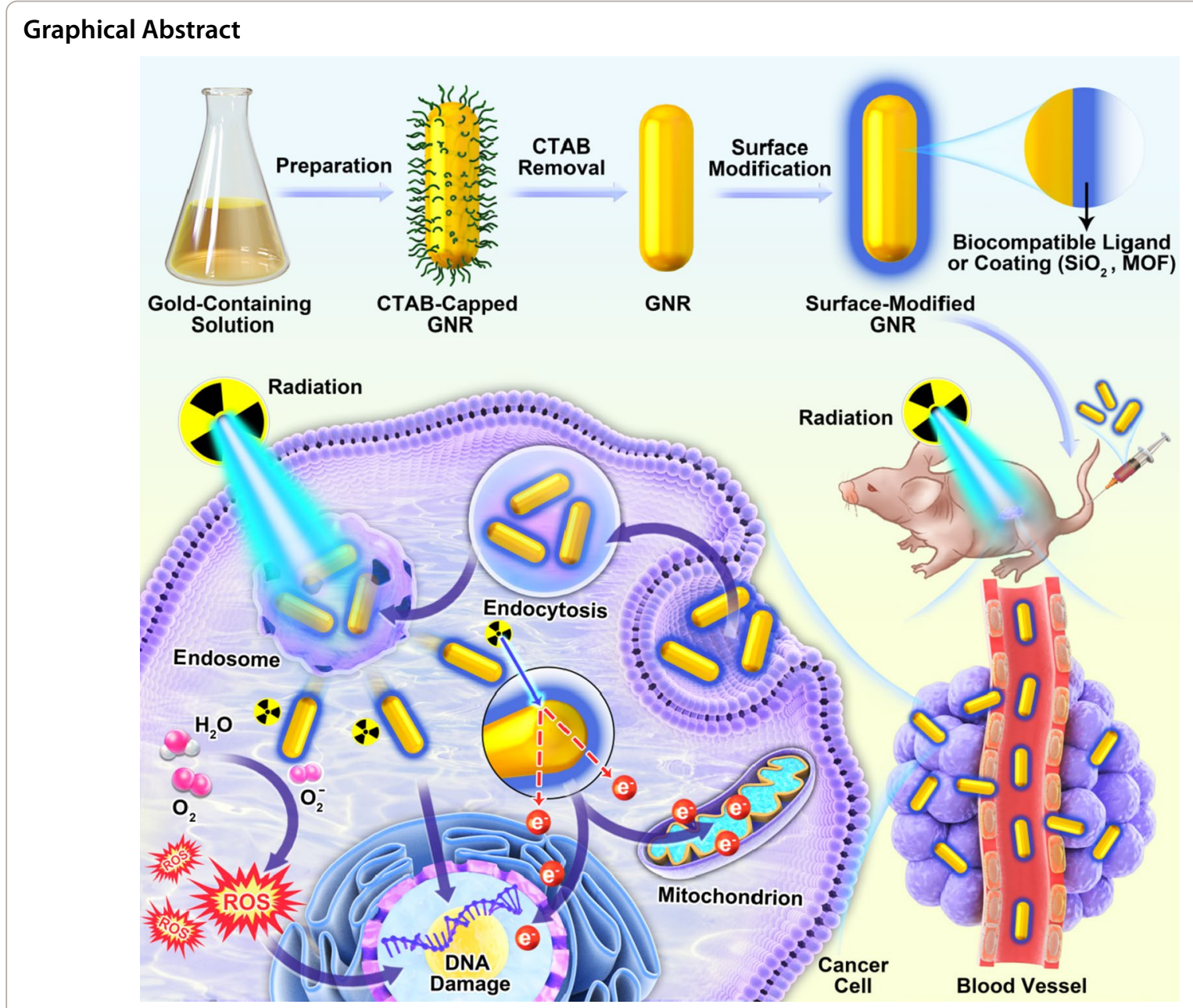

\section{Introduction}

Malignant tumors are one of the main causes of death in humans; radiation therapy is a local treatment modality for tumors, and more than $50 \%$ of patients with cancer need radiation therapy [1]. Radiation includes not only external radiation (X-rays, electron lines, etc.) generated by various types of machines or accelerators outside the body but also internal radiation (eg. alpha- and beta rays) generated by radioisotopes inside the body. The ionization effect caused by radiation can kill the tumor cells by directly destroy cellular DNA, or indirectly react with water molecule to produce reactive oxygen species (ROS) to damage DNA or other cellular components [1]. The role and status of radiation therapy in tumor therapy have become increasingly prominent and this method has emerged as one of the main means to treat malignant tumors; however, the radiation resistance of tumor cells remains a problem. As a type of ionizing radiationresponsive agents, radiosensitizers are commonly used in clinical practice to improve the effect of radiation therapy; however, traditional radiosensitizers, such as platinum-based drugs, show high toxicity and side effects and low selectivity to tumor cells. Therefore, radiosensitizers that can effectively target tumor tissues with good biocompatibility should be developed.

The fast development of nanotechnology applied in biomedicine has opened a new way for the diagnosis and treatment of tumors. Nanomaterials show passiveand active tumor targeting ability via the enhanced permeability and retention (EPR) effect and their surfaces modified with targeting molecules, respectively $[2,3]$. Nanomaterials with high atomic number (high-Z) have unique characteristics of photoelectric decay, and they have shown good potential in tumor radiation therapy as radiosensitizers. Many problems that restrict tumor radiation therapy may be overcome, and new opportunities may be explored to promote the further development of radiation therapy by introducing nanomaterials 
as radiosensitizers or sensitizer carriers into radiation therapy $[4,5]$.

Gold nanoparticles (GNPs), as high-Z materials $(Z=79)$, show various morphologies such as sphereshaped, rod-shaped, nanocage, and nanostar, and they have been widely explored in biomedicine [6, 7]. Gold nanorods (GNRs) belong to a type of GNPs; they have unique optical properties, good biocompatibility, easy-to-control surface modification, and have been extensively investigated in bioimaging, drug and gene delivery, biosensors, and cancer treatment $[8,9]$. GNRs show two absorbance maxima corresponding to the transverse surface plasmon resonance (TSPR) and longitudinal surface plasmon resonance (LSPR); the position of TSPR is near $520-530 \mathrm{~nm}$ and it does not change with the aspect (length/diameter) ratio of GNRs, but the position of LSPR can be tuned in the near-infrared (NIR) region (600-900 $\mathrm{nm}$ ) by adjusting the aspect ratio of GNRs [10]. When GNRs are irradiated with a laser, photon energy interacts with the lattice, vibration intensifies, temperature increases, and ROS form in the presence of molecular oxygen, that is, photothermal- and photodynamic effects are produced; this property enables GNRs to be involved in the synthesis of a variety of GNRs-based nanocomposites for photothermal therapy $[8,11-17]$. GNRs also elicit a photoacoustic (PA) effect, as such, they are considered a promising PA contrast agent $[8,18]$. Moreover, GNRs can be utilized for computed tomography (CT) imaging $[8,19]$ and radiation sensitization because of their strong X-ray absorption ability.

As high-Z materials, GNRs are potential radiosensitizers for radiation therapy [5-7]. In addition, GNR's excellent NIR photothermal property can help achieve the goal of reducing the radiation dose to reach the same radiation therapy efficacy. Before GNRs are applied to radiation therapy, their toxicity must be considered. To the best of our knowledge, there are very few reports regarding the research progress on the toxicity reduction and radiation therapy application of GNRs. In this manuscript, the research progress on the preparation, toxicity reduction, as well as radiation therapy application of GNRs are discussed (Fig. 1).

\section{Preparation of GNRs}

The preparation methods for synthesizing GNRs have progressed rapidly. The commonly used routes for preparation of GNRs include seed-mediated growth-, seedless-, template-, photochemical-, electrochemical- and sonochemical method; these routes have shown great advantages in the synthesis of GNRs with good dispersity and particle uniformity.

\section{Seed-mediated growth method}

Seed-mediated growth method was first introduced by Brown et al. [20]; it is relatively simple and inexpensive, and now it is the most commonly used route to prepare GNRs with high yield, high quality, and controllable size. The nucleation and growth of nanoparticles were conducted separately in this method [21]. The typical synthesis procedure $[21,22]$ is that the gold seeds prepared in advance were added to a growth solution having chemical precursors, which precipitated onto the seeds and grew into GNRs with a certain aspect ratio. During this procedure, the size of GNRs could be controlled by adjusting the molar ratio of seeds to gold salt in the growth solution and the addition of silver ions $\left(\mathrm{Ag}^{+}\right)$was very important to improve the yield and control the aspect ratio of GNRs [22], but there were many spherical GNPs in the product. To reduce the content of spherical GNPs, Nikoobakht et al. [23] improved the seed-mediated growth method using hexadecyltrimethylammonium bromide (CTAB) to replace sodium citrate, and GNRs with aspect ratios of 1.5-4.5 were obtained by adjusting $\mathrm{Ag}^{+}$concentration in the growth solution. In this research, the GNRs with longer aspect ratios of 4.5-10 were also successfully prepared using binary surfactants $C T A B$ and benzyldimethylhexadecylammonium chloride (BDAC) in the growth solution (Fig. 2). Moreover, researchers found that the aspect ratio and morphology of GNRs was dependent on the $\mathrm{pH}$ of the growth solution [24], and an impurity in CTAB was very important for GNRs formation [25].

\section{Seedless method}

Unlike the seed-mediated method, the nucleation and growth of nanoparticles are in the same reaction system for this method, thus, synthesizing seeds in advance is unnecessary. Ali et al. [26] synthesized the GNRs using a one-pot seedless method. The research results demonstrated that at $\mathrm{pH} 2$, the higher the concentration of sodium borohydride $\left(\mathrm{NaBH}_{4}\right)$, the more obvious red shift effect in the longitudinal peaks of growth solutions (Fig. 3A). Furthermore, this research indicated that the GNRs synthesized with seedless method showed the same aspect ratio $(4.8 \pm 0.6)$ as those prepared by the seeded method, both by adding silver nitrate $\left(\mathrm{AgNO}_{3}\right)$ $(270 \mu \mathrm{L} ; 4.0 \mathrm{mM})$ to the growth solutions; however, the former exhibited a larger particle size $(54.0 \times 11.2 \mathrm{~nm}$, Fig. 3B) compared with the latter $(25.0 \times 5.2 \mathrm{~nm}$, Fig. 3C). Yan et al. [27] developed a modified seedless method to synthesize high quality of small GNRs $((18 \pm 5 \mathrm{~nm}) \times(5 \pm 1 \mathrm{~nm}))$ at large-scale. The LSPR band peak of the as-prepared GNRs was around $780 \mathrm{~nm}$, and they exhibited excellent capabilities of photothermal therapy and PA imaging. 


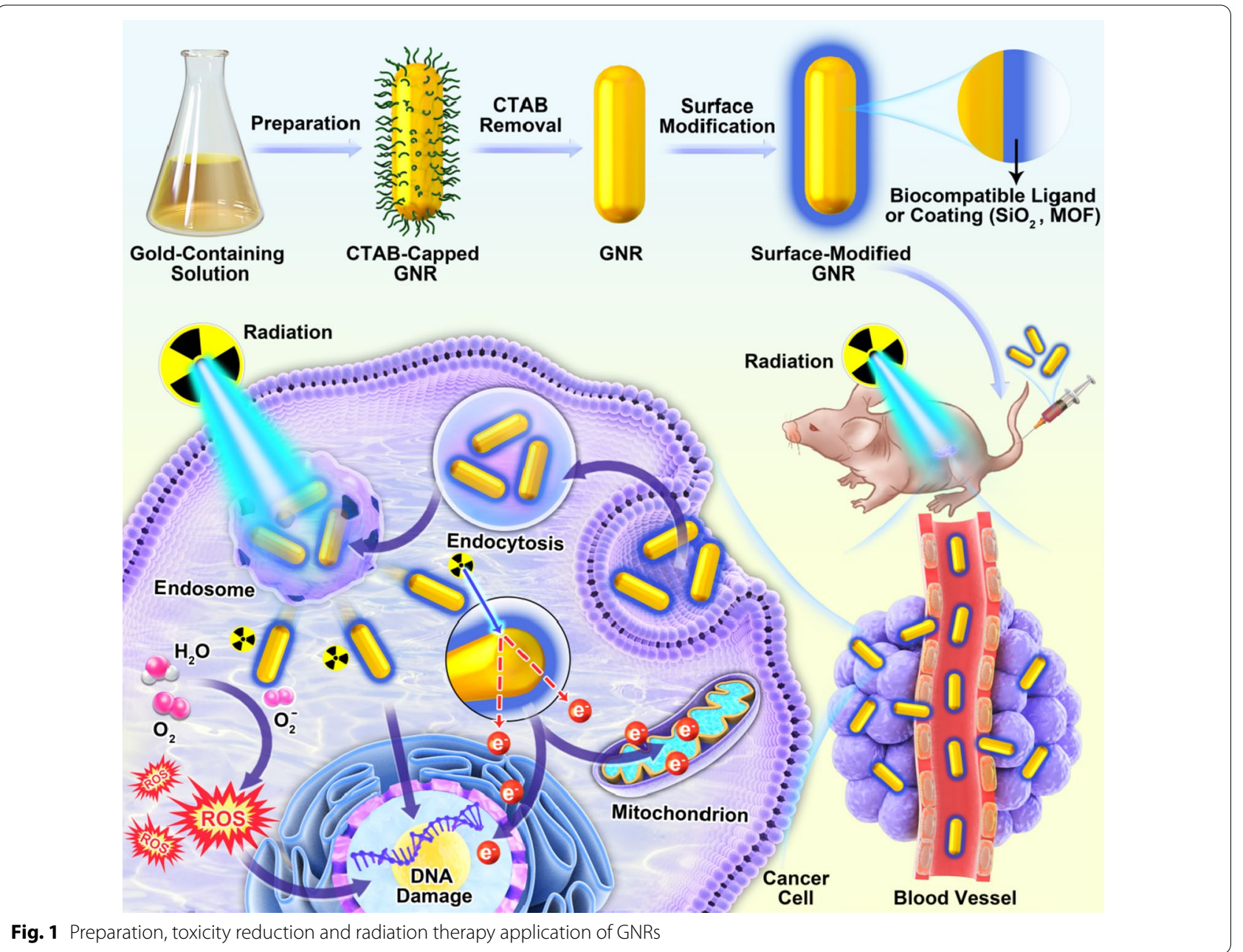

Fig. 1 Preparation, toxicity reduction and radiation therapy application of GNRs
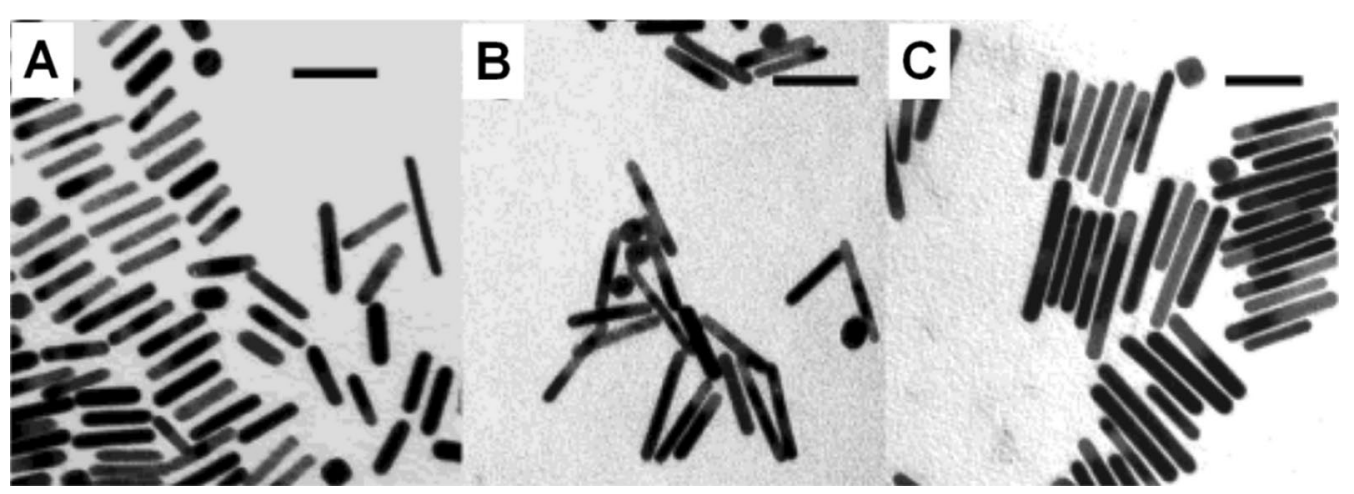

Fig. 2 Transmission electron microscopy (TEM) images of GNRs (prepared by seed-mediated growth method using binary surfactant mixture) with plasmon band energy at A 880, B 1130, and C $1250 \mathrm{~nm}$, respectively. The scale bar is $50 \mathrm{~nm}$ (Reproduced with permission [23]. Copyright 2003, American Chemical Society)

Template method

In the template method, porous materials with pore size ranging from nanometers to microns are used as templates to allow precursors to enter and react on the pore wall. Martin et al. [28] first introduced this method to synthesize gold nanofibrils in 1994. The desired GNRs 

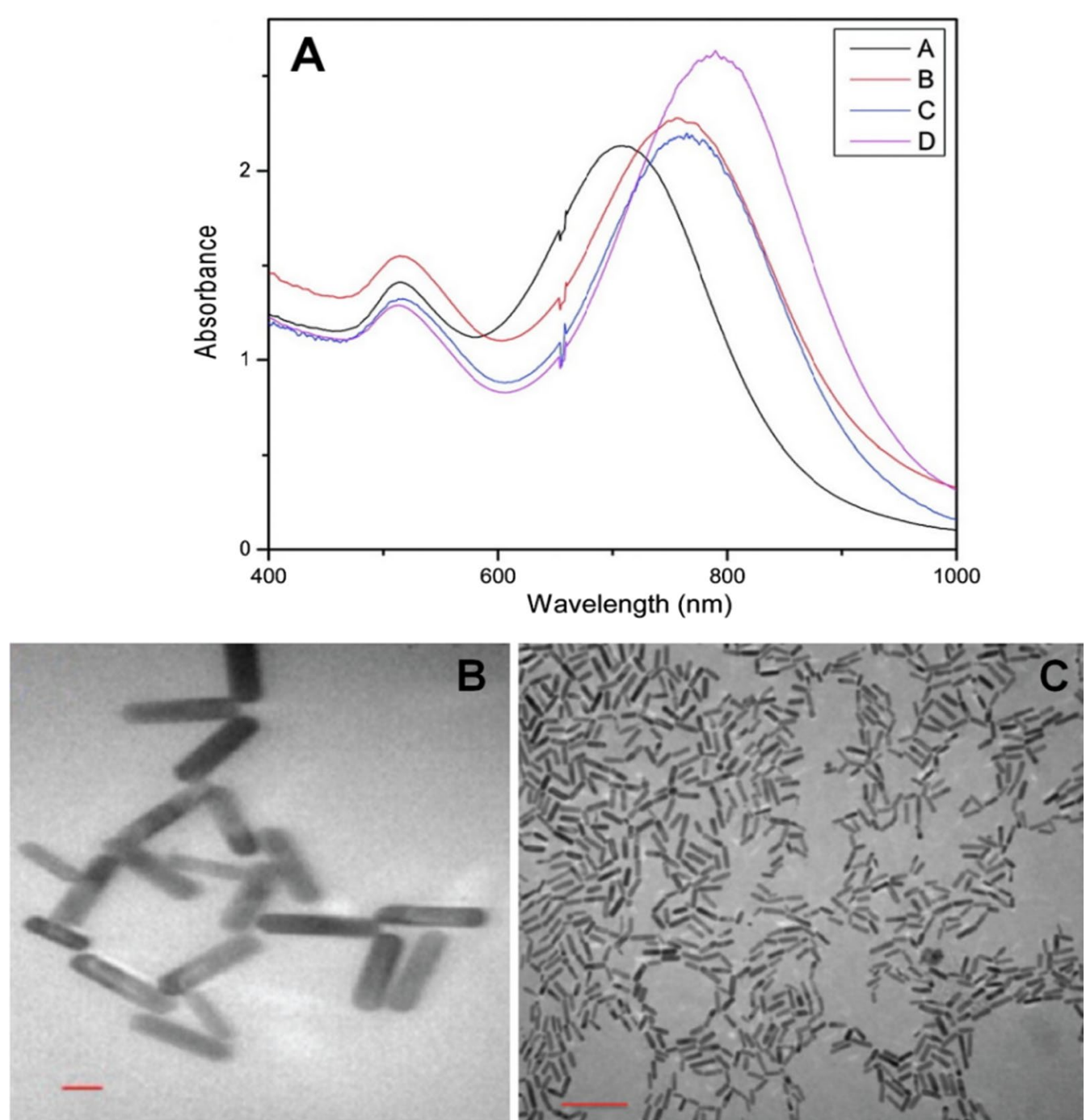

Fig. 3 A UV-vis-NIR absorption spectra of growth solutions with addition of different volume of $\mathrm{NaBH}_{4}(0.01 \mathrm{M})$ at pH 2: A 2, B 5, C 10, and D 15 $\mu$ L; TEM images of GNRs prepared with the seeded method (B) and seedless method (C). The aspect ratio (4.8) of the two GNRs is nearly the same. The bar indicates $20 \mathrm{~nm}$ for (B) and $100 \mathrm{~nm}$ for (C), respectively (Reproduced with permission [26]. Copyright 2012, American Chemical Society)

can be synthesized using this method combined with electrochemical precipitation-, sol-gel-, and gas phase precipitation method [29, 30]. As shown in Fig. 4, during synthesis, the growth of nanorods was limited by the diameter of the pores on a film, and the length of nanorods was controlled by the amount of $\mathrm{Au}$ atoms deposited in pores. Thus, the aspect ratio of GNRs could be controlled by adjusting the size and length of pores and the time of electrochemical deposition [30]. However, the size of GNRs was significantly affected by environmental factors during preparation, resulting in low productivity.

Gao et al. [31] improved the template method, employing silica nanotubes as template, for large-scale growth of GNRs with low polydispersity. In this route, the selectively functionalized inner surfaces of silica nanotubes realized the selective deposition of gold inside the nanotubes, and thus the GNRs having $17 \mathrm{~nm}$ of diameter (aspect ratio 3.5-21) formed after the template dissolved.

\section{Photochemical method}

Kim et al. [32] synthesized the GNRs via a photochemical method in the presence of $\mathrm{Ag}^{+}$. In this method, aqueous solution of CTAB and tetradodecyl ammonium bromide as growth solution and hydrogen tetracholoaurate $\left(\mathrm{HAuCl}_{4} \cdot 3 \mathrm{H}_{2} \mathrm{O}\right)$ as the precursor of gold were mixed. In order to loosen the micellar structure, then acetone and cyclohexane were added to the above 


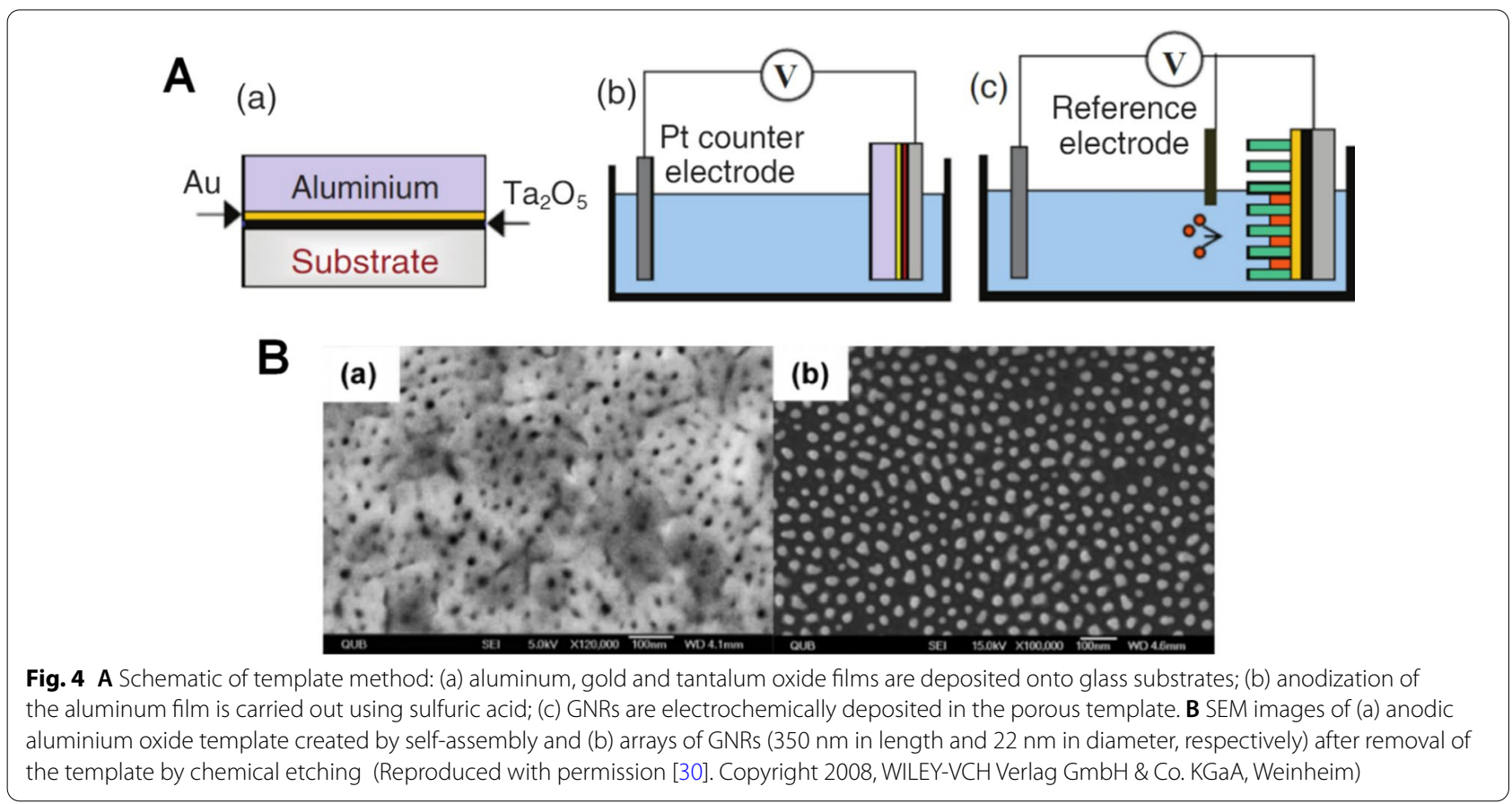

mixture solution; afterward, $\mathrm{AgNO}_{3}$ aqueous solution was added and the obtained mixture solution was irradiated with UV light $(254 \mathrm{~nm})$ for about $30 \mathrm{~h}$. The research results indicated that the synthesis of GNRs could be controlled by adjusting the $\mathrm{Ag}^{+}$concentration (Fig. 5), and the higher the $\mathrm{Ag}^{+}$concentration the larger the aspect ratio of GNRs, and the synthesis failed if $\mathrm{Ag}^{+}$ was not added. Toussi et al. [33] prepared the GNRs via the photochemical reduction of gold precursor in CTAB aqueous solution; the research results indicated that increasing of the CTAB concentration led to the obvious enhancement in the aspect ratio of GNRs.

\section{Electrochemical method}

Electrochemical method was introduced by Yu et al. [34] to synthesize GNRs. In this method, GNRs were synthesized in an electrochemical cell using platinum $(\mathrm{Pt})$ plate and gold $\mathrm{(Au}$ ) plate as anode and cathode, respectively, which were immersed in electrolytic solution having cationic surfactant $\mathrm{CTAB}$ and rod-inducing cosurfactant tetraoctylammonium bromide (TCAB). The gold plate at anode lost electrons via electrolysis, which was controlled by ultrasonic temperature, to become gold ions in electrolytic solution. One portion of gold ions moved to cathode and were reduced to elemental gold, the other portion of gold ions in electrolytic solution were
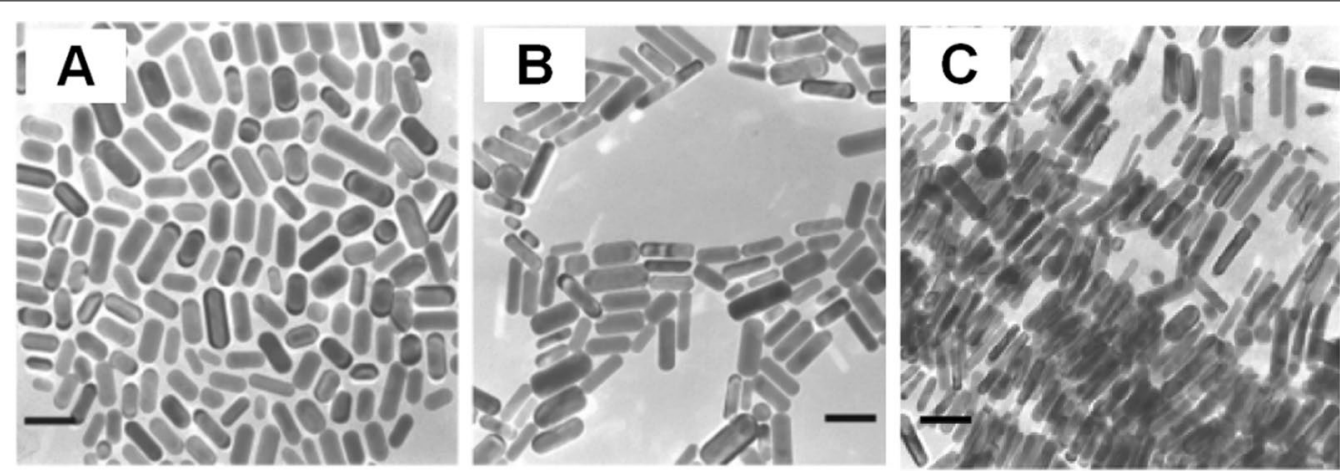

Fig. 5 TEM images of GNRs prepared via the photochemical method with A 15.8, B 23.7, and C $31.5 \mu \mathrm{L}$ of silver nitrate solution; the average aspect ratio of the GNRs is 2.8 (A), 3.5 (B), and 4.8 (C), respectively. The bar indicates $50 \mathrm{~nm}$ (Reproduced with permission [32]. Copyright 2002, American Chemical Society) 
reduced by $C T A B$ and turned into a midbody, then the CTAB-conjugated midbody together with elemental gold attached to the Pt plate formed the nanorods (Fig. 6). During this process, CTAB not only acted as electrolyte but also prevented nanorods from aggregation, and TCAB could induce GNRs formation. In this research, the aspect ratio of GNRs could be controlled by adjusting the current density or the $\mathrm{CTAB} / \mathrm{TCAB}$ ratio. Chang et al. [35] utilized a modified electrochemical route to prepare the GNRs with average aspect ratio ranging from 1 to 7 ; they found that the larger the total area of immersed silver plate at the end of electrolysis the longer the obtained GNRs.

\section{Sonochemical method}

Okitsu et al. [36] reported the synthesis of GNRs using the sonochemical method. The research demonstrated that the obtained GNRs showed less than $50 \mathrm{~nm}$ of size, and the average aspect ratio of GNRs decreased as the $\mathrm{pH}$ value of the solution increased (Fig. 7), and GNPs with irregular morphologies would be formed if the $\mathrm{pH}$ value of solution increased to 7.7 .

Till now, the methods discussed above can achieve preparing GNRs with good uniformity and dispersity, and the size and aspect ratio of GNRs can be controlled by adjusting various experimental parameters during synthesis. However, for the potential biomedical applications of GNRs, green and more repeatable methods for GNRs preparation should be further developed.

\section{Toxicity reduction of GNRs}

GNRs are able to maintain their colloidal stability in the presence of a certain amount of ligands on their surface, otherwise, they will aggregate irreversibly. The most common ligand on the surface of GNRs is CTAB, which acts as cationic surfactant. Although CTAB is able to significantly increase the productivity of GNRs during synthesis, the CTAB-capped GNRs show cytotoxicity owing to the positive charge of $C T A B$ and thus induce cell necrosis in vitro [37]. Therefore, removing or replacing $\mathrm{CTAB}$
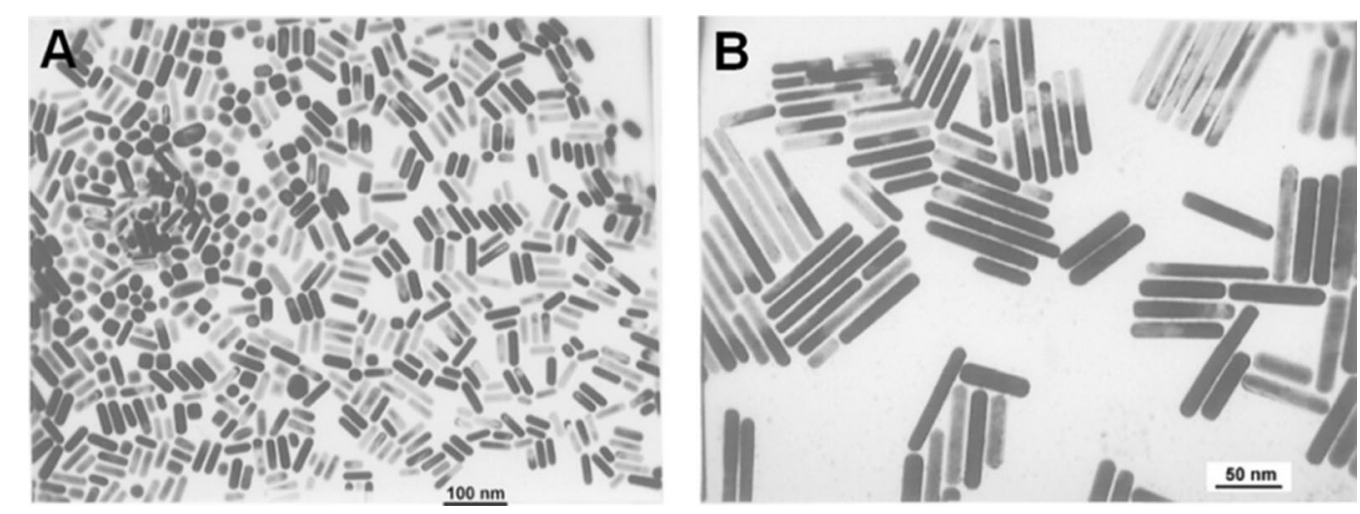

Fig. 6 TEM images of GNRs with different mean aspect ratios synthesized via electrochemical method:2.6 (A) and 7.6 (B) (Reproduced with permission [34]. Copyright 1997, American Chemical Society)
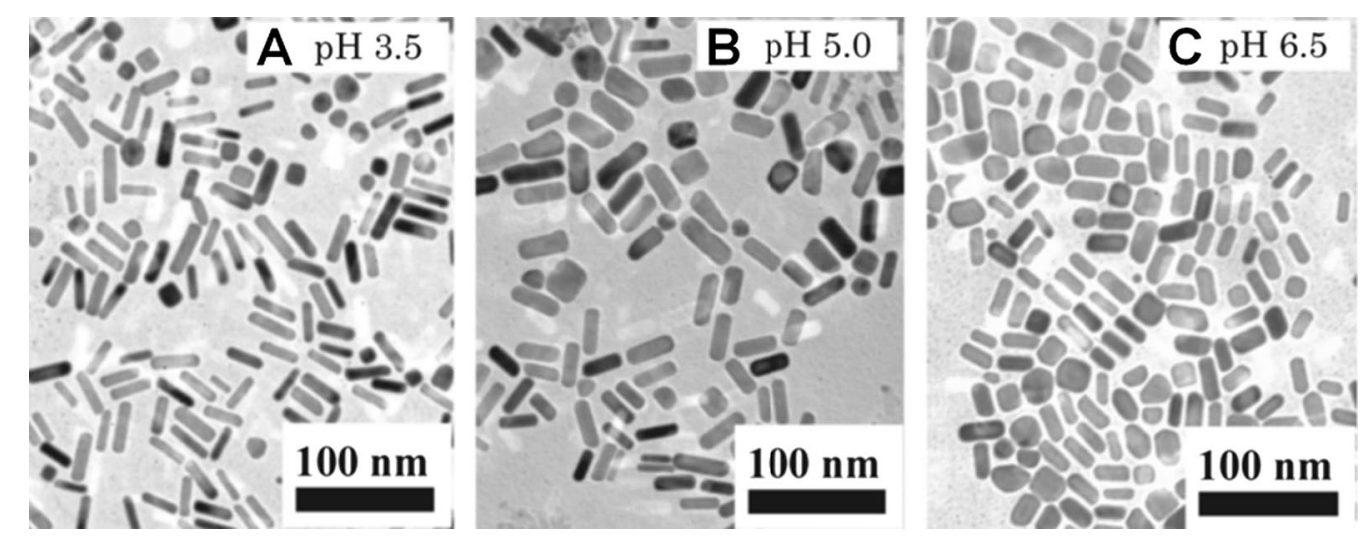

Fig. 7 TEM images of GNRs prepared in different pH solutions with $\mathbf{A}$ pH 3.5, B pH 5.0, and $\mathbf{C}$ pH 6.5 after 180 min irradiation under argon (Reproduced with permission [36]. Copyright 2009, American Chemical Society) 
is an indispensable step before any further biological investigations on GNRs. The toxicity reduction of GNRs involves CTAB removal/replacement and the concomitant surface modification. Four routes, including centrifugation-washing-, phase transfer-, ligand exchange-, and surface coating method, are discussed for toxicity reduction of GNRs in this manuscript.

\section{Centrifugation-washing method}

Centrifugation-washing method is the basic and commonly used route to remove $C T A B$ on the surface of GNRs [38-41]. This method removes the excess CTAB on the surface of GNRs by centrifuging GNRs solution and washing GNRs with deionized (DI) water. Although this method is capable to remove most of the CTAB on GNRs, it is always accompanied by other method (e.g. phase transfer-, ligand exchange-, and surface coating method) for further CTAB removal or replacement.

\section{Phase transfer method}

The thiol-containing ligands are commonly employed to replace the CTAB on GNRs thanks to their strong affinity to surface of $\mathrm{Au}$. In a typical phase transfer procedure, the CTAB-capped GNRs were transferred from aqueous phase into an organic solvent with hydrophobic thiolcontaining ligands, which could replace CTAB by being conjugated onto the surface of GNRs.

Among the thiol-containing ligands, 11-mercaptoundecanoic acid (MUA) as a thiol-containing carboxylic acid is often utilized to replace CTAB because that their carboxyl terminals could be further conjugated with biomolecules. For instance, Su et al. [42] replaced the CTAB on GNRs using MUA via a round-trip phase transfer route. The CTAB-capped GNRs aqueous solution, waterimmiscible ionic liquid (IL) 1-butyl-3-methylimidazolium bis(trifluoromethanesulfonyl)imide ([BMIM][Tf2N]) and MUA/IL solution were firstly mixed and then vortex stirring was carried out, and finally the MUA-capped GNRs were obtained via ligand exchange mediated by IL. The obtained MUA-capped GNRs had improved colloidal stability and biocompatibility. Similarly, Li et al. [43] prepared the MUA-capped GNRs by a round-trip phase transfer method; the obtained MUA-capped GNRs were further modified by albumin and loaded with paclitaxel (PTX) successively for photothermo-chemotherapy of tumor model in mice. Casas et al. [44] reported that CTAB on GNRs could be replaced by MUA via a double phase transfer ligand exchange using dodecanethiol (DDT); the obtained MUA-capped GNRs kept the morphology and plasmon peak position compared with those of CTAB-capped GNRs.

Other thiol-containing ligands, such as phospholipid bilayer and partially thiolated polyamidoamine
(PAMAM) dendrimer, were also reported for replacing CTAB by phase transfer method. Lee et al. [45] replaced the CTAB on GNRs using a phospholipid bilayer via a water-chloroform phase transfer route mediated by thiolated PEG. During the procedure, two different thiolated lipid molecules 1,2-dipalmitoyl-sn-glycero-3-phosphothioethanol (DPPTE) and 1,2-distearoyl-sn-glycero3-phosphocholine (DSPC) were successively introduced to GNRs surface in chloroform and water, respectively, and thus a lipid bilayer was formed on GNRs surface owing to the hydrophobic interaction between DPPTE and DSPC. These lipid bilayer-capped GNRs showed good stability in PBS and $\mathrm{NaCl}$ solutions. Huang et al. [46] reported a phase transfer method for synthesizing partially thiolated polyamidoamine (PAMAM) G4.0 dendrimer-capped GNRs. They firstly obtained the MUAcapped GNRs, then the MUA-capped GNRs were further customized with partially thiolated polyamidoamine (PAMAM) G4.0 dendrimer. The synthesized dendrimercapped GNRs demonstrated no obvious change in plasmon peak width or position.

\section{Ligand exchange method}

This method refers to replacing CTAB on GNRs with other bicompatible ligands, and it is actually involved in the phase transfer method described above.

In this method, poly(ethylene glycol) (PEG) or PEGbased polymer is the commonly used ligand. Buckway et al. [39] removed the excess CTAB on the surface of GNRs via centrifugation and washing by DI water, and then utilized PEG to coat the GNRs. Dickerson et al. [40] reported that the excess CTAB on GNRs could be removed by that GNRs solution was centrifuged twice at a rate of $20,000 \times g$ for $15 \mathrm{~min}$ and re-dispersed in DI water, and then they used thiolated poly (ethylene) glycol (mPEG-SH) to bind to the surface of GNRs. Liu et al. [47] replaced CTAB on GNRs with polythiol PEG-based copolymer to produce an effective NIR photothermal agent. The research demonstrated that the cytotoxicity of GNRs modified by polythiol PEG-based copolymer largely decreased compared to the original CTAB-capped GNRs. Other polymers, such as polyvinyl alcohol (PVA) and polyvinylpyrrolidine (PVP), were also reported for ligand exchange of GNRs. Kinnear et al. [48] removed the majority of CTAB on GNRs using biocompatible polymer polyvinyl alcohol (PVA) as coating. The obtained PVAGNRs showed good biocompatibility on human blood monocyte derived macrophages (MDMs). Zhao et al. [49] removed the excess CTAB on GNRs by washing with DI water, and then used polyvinylpyrrolidone (PVP) to coat the GNRs as photosensitizers for two-photon photodynamic therapy in vitro; the in vitro cellular cytotoxicity 
experiment demonstrated that the PVP-modified GNRs had excellent biocompatibility.

As described in phase transfer method section [4244], thiol-containing carboxylic acids are often utilized to be conjugated with GNRs. Garabagiu et al. [41] reported that the GNRs solution was centrifuged 3 times at $10,000 \mathrm{rpm}$ to remove the CTAB and then employed 3-mercaptopropionic acid (MPA) for further surface functionalization of GNRs. Dai et al. [50] utilized a place exchange reaction (carried out inside an ionic exchange resin) between CTAB-capped GNRs and MUA to replace CTAB by MUA. He et al. [51] removed the excess CTAB on GNRs by centrifugation and washing, and then added $\mathrm{NaBH}_{4}$ and ethanol solution of MUA to the GNRs for the formation of MUA layer on the surface of GNRs. The research results indicated that the MUA-capped GNRs showed remarkably improved biocompatibility.

\section{Surface coating method}

Employing silica $\left(\mathrm{SiO}_{2}\right)$ or metal-organic frameworks (MOFs) to coat GNRs is also an efficient route to improve the colloidal stability and biocompatibility of GNRs. $\mathrm{SiO}_{2}$ has been widely used to coat GNRs since it is able to yield products with good dispersity and biocompatibility and involves easy surface modification [52-57]. MOFs, as a new type of porous materials with unique properties, have also been widely utilized to coat GNRs to synthesize GNR@MOF core-shell structures for biomedical applications. For instance, Shang et al. [58] replaced CTAB on GNRs with MUA and then synthesized Au NR@ MIL-88(A) core-shell structure as a tripe-modality imaging agent. Li et al. [59] prepared the zeolitic imidazolate framework-8 (ZIF-8)-coated GNRs with coreshell nanostructure for cancer therapy. Zeng et al. [60] reported the growth of porphyrinic MOFs on the surface of GNRs for constructing core-shell Au NR@MOFs (MOF: $\mathrm{Zr}_{6}(\mathrm{TCPP})_{1.5}(\mathrm{TCPP}=$ tetrakis (4-carboxyphenyl) porphyrin)) as a theranostic nanoplatform.

The ligand or coating utilized for toxicity reduction of GNRs discussed above are summarized in Table 1.

\section{GNRs as radiosensitizers in radiation therapy}

Nanostructures with high- $Z$ are ideal radiosensitive materials for radiation enhancement. Taking the $\mathrm{X}$-ray absorption by materials as an example, the X-ray absorption coefficient $(\mu)$, incident X-ray energy $(E)$, and atomic number $(\mathrm{Z})$ of materials are based on the following relationship: $\mu=\rho Z^{4} /\left(\mathrm{AE}^{3}\right)$, where $\rho$ and $A$ are the density and atomic mass of materials, respectively [61]. Nanostructures with high- $\mathrm{Z}$ are able to enhance $\mathrm{X}$-ray absorption in local tissues and effectively release low-energy electrons to generate more free radicals, and the energy (deposited efficiently by free radicals and electrons) can
Table 1 Ligand or coating utilized for toxicity reduction of GNRs discussed in this manuscript

\begin{tabular}{ll}
\hline Ligand or coating utilized & Refs. \\
\hline PEG or PEG-based polymer & {$[39,40,47]$} \\
PVA & {$[48]$} \\
PVP & {$[49]$} \\
MPA & {$[41]$} \\
MUA & {$[42-44,50,51,58]$} \\
Phospholipid bilayer & {$[45]$} \\
Partially thiolated polyamidoamine (PAMAM) den- & {$[46]$} \\
drimer & \\
$\mathrm{SiO}_{2}$ & {$[52-57]$} \\
$\mathrm{MOFs}$ & {$[58-60]$} \\
\hline
\end{tabular}

cause damage to DNA [62]. Element Au with high-Z $(Z=79)$ make GNRs widely used in external-and internal radiation therapy. GNRs as radiosensitizers in radiation therapy is divided into two parts (external- and internal radiation therapy) for discussion in this manuscript.

\section{GNRs as radiosensitizers in external radiation therapy}

GNRs are able to cause sensitization with external radiation (e.g. X-rays) in vitro and in vivo. GNRs are often modified with PEG or a layer of silica to improve their colloidal stability in radiation therapy. Besides, if GNRs or GNRs-based nanocomposites are conjugated with targeting ligands, such as specific antibody and peptide, their accumulation in tumor site will increase greatly, and thus their radiation therapy efficacy will be improved.

$\mathrm{Xu}$ et al. [63] prepared arginine-glycine-aspartate (RGD)-conjugated GNRs with a layer of silica (RGDGNRs) to enhance the radiation therapy of melanoma cells. The RGD-GNRs could be internalized into A375 melanoma cells by integrin $\alpha v \beta 3$-receptor mediated endocytosis. The following trend of radiosensitizing effect of treatment groups was demonstrated in this research: RGD-GNRs plus radiation (X-ray) $>$ radiation alone $>$ RGD-GNRs $>$ GNRs, attributed to that RGDGNRs could downregulate $\alpha v \beta 3$ expression. The cell cycle of A375 cells treated by GNRs, RGD-GNRs, radiation alone, and RGD-GNRs plus radiation was arrested at the $\mathrm{G} 2 / \mathrm{M}$ phase of $35 \% \pm 2.65 \%, 36.14 \% \pm 0.35 \%$, $40.9 \% \pm 0.35 \%$, and $46.5 \% \pm 1.2 \%$, respectively. Zhao et al. [53] investigated the radiosensitizing effect of RGD-conjugated and mesoporous silica-coated GNRs (GNRs@ $\left.\mathrm{mSiO}_{2}-\mathrm{RGD}\right)$ multifunctional nanoprobe in MDA-MB-231 triple-negative breast cancer (TNBC) cells in response to megavoltage (MV) radiation. The research results demonstrated that GNRs@mSiO $2_{2}$ RGD plus radiation had a synergistic effect of increasing the population of MDA-MB-231 cells in the G2/M 
phase and the proportion of apoptotic cells. Wolfe et al. [64] synthesized goserelin-conjugated GNRs (gAuNRs) for radiation therapy of prostate cancer. The targeting ligand goserelin promoted the internalization of GNRs within prostate cancer (PC3) cells and enhanced the sensitization of prostate tumors to MV radiation therapy in vivo. In this research, the gAuNRs, whose TEM image was shown in Fig. 8A, accumulated inside the PC3 cells at higher concentration than PEGlated GNRs (pAuNRs) (Fig. 8B, C). The quantitative inductively coupled plasma-mass spectrometry (ICP-MS) data showed that the concentration of gAuNRs within cells reached the maxima at $24 \mathrm{~h}$ of post-incubation, which was 5 times greater than pAuNRs. Moreover, the mice treated with gAuNR and radiation therapy showed obviously enhanced tumor-growth delays, but not delay with radiation therapy alone (Fig. 8D).
Khoo et al. [65] also reported goserelin-conjugated GNRs for radiosensitization of prostate cancer using erbium (Er)-filtered X-ray. The research demonstrated that the combined treatment of goserelin-conjugated GNRs and Er-filtered X-ray irradiation had more obvious tumor growth inhibition effect in mice bearing prostate cancer xenografts tumors than radiation treatment only. Chang et al. [66] synthesized two types of peptide (RGD and ACPP)-coated core-shell Au@Se nanocomposites for synergistic radiochemotherapy using the radiosensitization effect of GNRs and the antitumor activity of Se NPs. The research exhibited that the nanocomposite treatment plus X-ray could induce apoptosis of A375 melanoma cells and trigger intracellular ROS overproduction, and could further suppress the tumor growth in vivo. Ma et al. [67] investigated the effect of the shape of gold nanostructures on the efficiency of X-ray radiation therapy. They prepared gold nanomaterials with
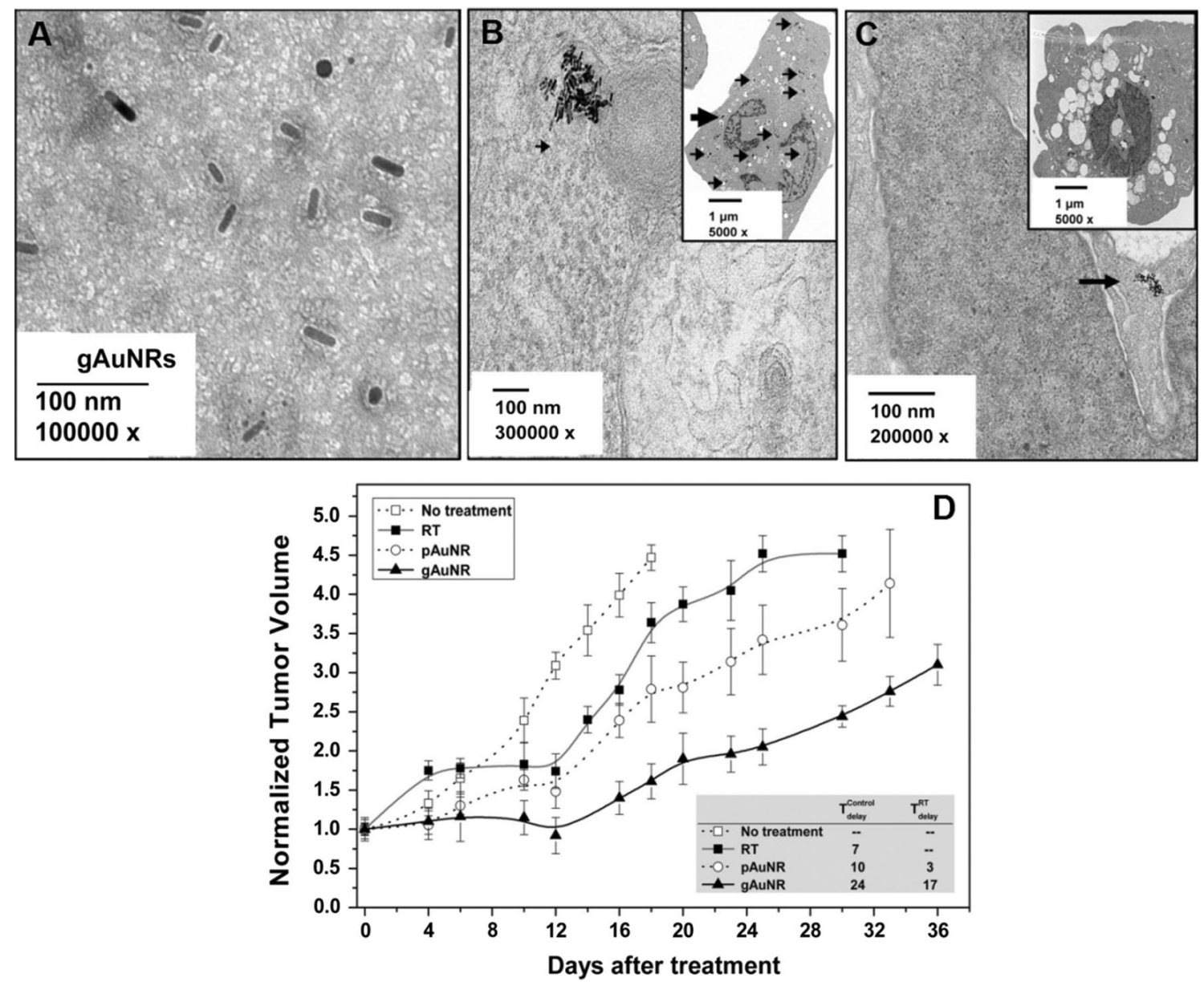

Fig. 8 TEM image of gAuNRs (A); TEM images of PC3 cells treated with gAuNRs (B) and pAuNRs (C) for $24 \mathrm{~h}$ of incubation. Arrows point to AuNRs; D Tumor-growth in nude mouse xenograft models with and without treatment by AuNRs before radiation therapy (RT) with $6 \mathrm{MV}$ beam. The inside is the table showing tumor-growth delays, comparing the groups that given either gAuNR and RT (filled triangle) or pAuNR and RT (open circle) with the groups that given only RT (filled square) and no treatment (open square) (Reproduced with permission [64]. Copyright 2015, Elsevier Ltd) 
similar average size of about $50 \mathrm{~nm}$ but different shapes, including spherical GNPs, gold nanospikes (GNSs), and GNRs, and then coated them with PEG molecules. The research demonstrated that these gold nanomaterials incubated with KB cells for $24 \mathrm{~h}$ showed cellular internalization efficiency in the order of GNPs $>$ GNSs $>$ GNRs, and the radiosensitization effect of these gold nanomaterials exhibited the same order as that of cellular internalization efficiency, and the sensitization enhancement ratios (SERs) corresponding to the treatments of the above gold nanostructures (GNPs, GNSs, and GNRs) were $1.62,1.37$, and 1.21 , respectively. These results indicated that the radiosensitization effect of gold nanostructures was determined by the internalized amount of gold atoms. The studies on radiosensitization mechanism showed that gold nanostructures could induce ROS level and cell cycle redistribution, and thus to improve the radiosensitization effect.

The high NIR photothermal conversion efficiency and strong X-ray attenuation abilities of GNRs make them as photothermal agents and radiosensitizers in synergistic treatment of photothermal therapy and radiation therapy. The mechanism of this synergistic treatment is the following: hyperthermia increase the temperature of local tumor tissues, soften blood vessels, promote blood circulation and oxygen transport in tumor microenvironment, improve the sensitivity of hypoxic tumor cells to radiation, and inhibit the repair of radiation injury of tumor cells. The combination of radiation therapy with photothermal therapy using GNRs can reduce radiation dose and improve radiation therapy efficacy. Huang et al. [19] synthesized folic acid-conjugated silica-coated GNRs (GNR-SiO ${ }_{2}$-FA) to selectively target $\mathrm{MGC} 803$ gastric cancer cells and enhance the effect of radiation therapy and photothermal therapy on MGC803 cells. The TSPRand LSPR wavelength of the obtained GNR-SiO ${ }_{2}-\mathrm{FA}$ was $527 \mathrm{~nm}$ and $732 \mathrm{~nm}$, respectively. The thin-section TEM image of MGC803 cells treated by $\mathrm{GNR}^{-\mathrm{SiO}_{2}}$-FA indicated that $\mathrm{GNR}-\mathrm{SiO}_{2}-\mathrm{FA}$ could be endocytosed via the folate receptor-mediated path in endosomes (Fig. 9A). Under X-ray irradiation, the viability of MGC803 cells treated by $\mathrm{GNR}-\mathrm{SiO}_{2}$-FA for $24 \mathrm{~h}$ decreased as GNR$\mathrm{SiO}_{2}$-FA concentration increased (Fig. 9B). The GNR$\mathrm{SiO}_{2}$-FA demonstrated strong X-ray attenuation for in vivo X-ray/CT imaging, and the tumor targeting ability of $\mathrm{GNR}^{-\mathrm{SiO}_{2}}$-FA was exhibited by the real-time in vivo

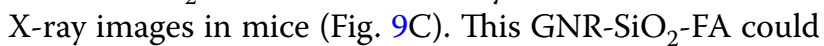
be utilized for X-ray/CT imaging-guided and targeted radiation therapy and photothermal therapy.

Li et al. [68] reported that the radiosensitizing effect of RGD-conjugated GNRs (RGD-GNRs) combined with NIR irradiation was greater than that of RGDGNRs alone in A375 cells, and thus the apoptosis of cells increased and the proportion of cells in the more radioresistant S phase decreased. Movahedi et al. [69] investigated the photosensitivity and radiosensitivity of folate-conjugated GNRs (AuNR-FA) on KB nasopharyngeal carcinoma cells. ICP-MS analysis confirmed that the uptake of AuNR-FA in KB cells was higher than that of GNRs. MTT assay showed that the combination of photothermal therapy and radiation therapy using AuNR-FA significantly reduced the viability of KB cells. Sun et al. [70] fabricated the GNRs coated with human oral squamous KB cancer cell membrane (GNR@Mem), as shown in Fig. 10A, for targeting KB cancer cells. The obtained GNR@Mem exhibited high photothermal transfer efficiency and superb stability under $980 \mathrm{~nm}$ NIR light (Fig. 10B), as well as high radiosensitizing ability. Compared with the control groups, the combination treatment of X-ray and NIR light irradiation improved the therapeutic effect, demonstrated in the number of $\mathrm{y}$-H2AX foci (Fig. 10C) and cell apoptosis and necrosis ratio (Fig. 10D). This research showed that the GNR@Mem suppressed the xenograft KB tumor growth under the irradiation of NIR light and X-ray. In addition, the TEM images of tumors of mice (Fig. 10E, F) and distribution of GNRs in tumor $24 \mathrm{~h}$ post-injection (Fig. 10G) both indicated that more GNRs were accumulated in the tumor of GNR@Mem group than that of GNR@PEG group, demonstrating the targeting ability of the cancer cell membrane on GNRs.

Gamma rays generated by machines outside the body were also utilized to study the external radiation therapy application of GNRs. Masood et al. [71] used the GNR-SphK siRNA nanocomposite [GNRs loaded by short interfering RNA (siRNA) targeting the antiapoptotic sphingosine kinase (SphK1) gene] to induce radiation sensitization in head and neck squamous cell carcinoma (HNSCC) tumor in mice. The research demonstrated that GNR-SphK siRNA nanocomposite could efficiently deliver SphK siRNA to HNSCC cells and sensitize the tumor to radiation from a gamma cell 40 irradiation machine with ${ }^{137} \mathrm{Cs}$ source. Compared with control group (GNR-GFP siRNA plus radiation treatment), the GNR-SphK1 siRNA plus radiation treatment group resulted in over 50\% tumor regression. Furthermore, this GNR-SphK siRNA nanocomposite could inhibit the tumor growth significantly with radiation at low dosage of $5 \times$ lower than that utilized in clinical radiation therapy. Koosha et al. [72] reported the PEGcoated AuNR@MS nanostructure (GNRs were coated by $\mathrm{mSiO}_{2}$ ) for radiation therapy study. The research found that AuNR@MS nanostructures at high concentrations showed obvious radiosensitization effect on CT-26 cells under radiation of gamma ray (4 Gy) from a cobalt 60 (Co-60) machine. 

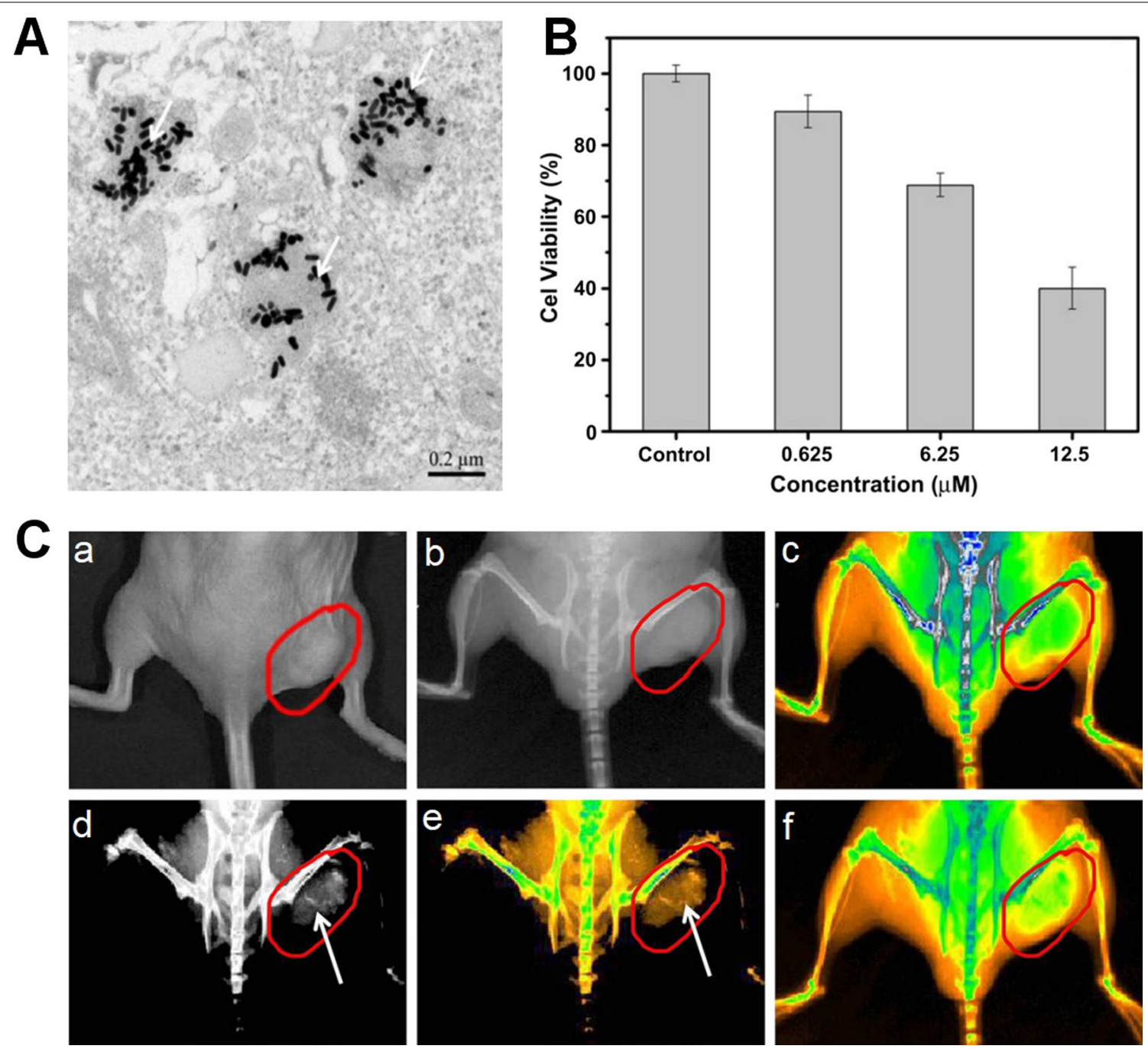

Fig. 9 A The thin-section TEM image of MGC803 cells incubated with $50 \mathrm{mM}$ of GNR-SiO 2 -FA for $2 \mathrm{~h}$; $\mathbf{B}$ The viability of MGC803 cells incubated with $100 \mathrm{~mL}$ of $\mathrm{GNR}_{-} \mathrm{SiO}_{2}-\mathrm{FA}$ with various concentration for $24 \mathrm{~h}$ under $6 \mathrm{~Gy}$ of $\mathrm{X}$-ray irradiation; C Real-time in vivo X-ray images after intravenous injection of $\mathrm{GNR}_{-} \mathrm{SiO}_{2}-\mathrm{FA}$ in nude mice at different time points: (a) Photograph of the tumor tissue; (b) X-ray image at $0 \mathrm{~h}$; (c) X-ray image at $0 \mathrm{~h}$ (in color); (d) X-ray image at $12 \mathrm{~h}$, (e) X-ray image at $12 \mathrm{~h}$ (in color); (f) X-ray image at $24 \mathrm{~h}$ (in color) (Reproduced with permission [19]. Copyright 2011, Elsevier Ltd)

\section{GNRs as radiosensitizers in internal radiation therapy}

GNRs were also labeled by various radionuclides, such as ${ }^{90} \mathrm{Y}$ and ${ }^{125} \mathrm{I}$, for internal radiation therapy of cancer. Buckway et al. [39] synthesized PEGylated GNRs (PEGGNRs) to achieve hyperthermia; they also used HPMA copolymers labeled with ${ }^{111}$ In and ${ }^{90} \mathrm{Y}$ for SPECT imaging and radiation therapy investigations, respectively (Fig. 11). The research demonstrated the potential of hyperthermia mediated by GNRs in sensitizing tumors to radiation therapy and the combination of photothermal therapy and internal radiation therapy was effective in DU-145 prostate tumor-bearing mouse model. Gao et al. [73] utilized folic acid-conjugated silica-coated GNRs
(GNRs@SiO 2 -FA) in combination with iodine-125 $\left({ }^{125} \mathrm{I}\right)$ seeds implantation for radiation therapy of cancer cells. They verified that the concentration of GNRs@SiO $-\mathrm{FA}$ smaller than $40 \mu \mathrm{g} / \mathrm{mL}$ was safe for biological activity of hepatocellular carcinoma cells (HepG2) and GNRs@ $\mathrm{SiO}_{2}$-FA could enter the cytoplasm via endocytosis. The ${ }^{125}$ I seeds implantation were used to irradiate cells in this research, and the results demonstrated that the combination of GNRs@SiO 2 -FA as radiosensitizer with ${ }^{125}$ I seeds effectively induced apoptosis in cells by increasing the protein expression of Bax and caspase- 3 , and this combination also inhibited the protein expression of $\mathrm{Bcl}-2$ and Ki-67. 

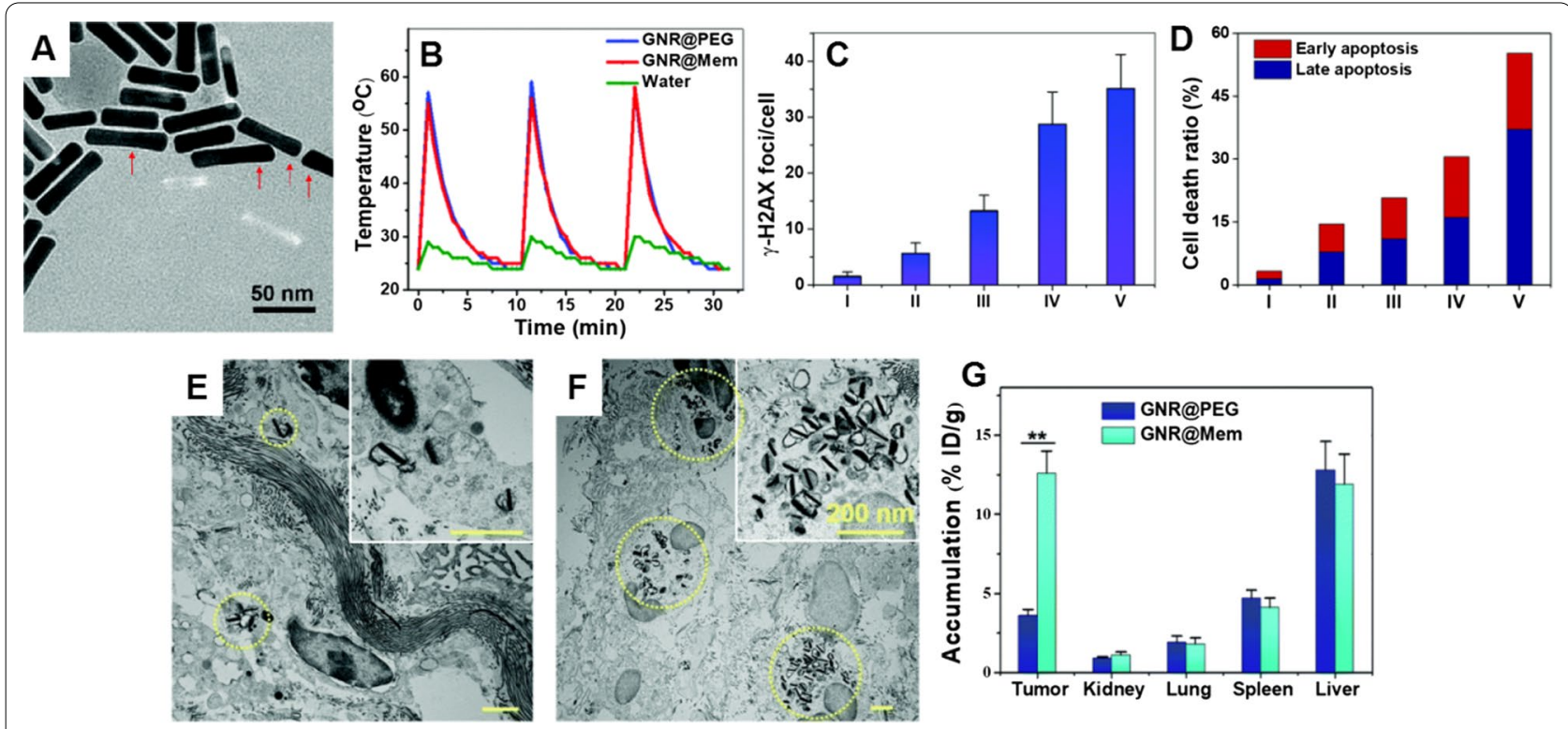

Fig. 10 A TEM image of GNR@Mem; B temperature of GNR@Mem dispersion as a function of irradiation time under $980 \mathrm{~nm}$ light at $0.5 \mathrm{~W} / \mathrm{cm}^{2}$ for 1 min (the GNR concentration was $100 \mathrm{mg} / \mathrm{mL}$ ); Quantitative analysis of $\mathbf{C} \mathrm{\gamma}-\mathrm{H} 2 \mathrm{AX}$ foci density, and $\mathbf{D}$ cell apoptosis and necrosis ratio in different treatment groups (I—Control, II—4 Gy, III—GNR@PEG + 4 Gy, IV—GNR@Mem + 4 Gy, V—GNR@Mem + 4 Gy + NIR; the GNR concentration was $20 \mathrm{mg} / \mathrm{mL}$ ); TEM images of the tumors in mice treated by E GNR@PEG and F GNR@Mem (scale bars are $200 \mathrm{~nm}$ ); $\mathbf{G}$ Tissue distribution of GNRs $24 \mathrm{~h}$ after i.v. injection. (Reproduced with permission [70]. Copyright 2020, Royal Society of Chemistry)

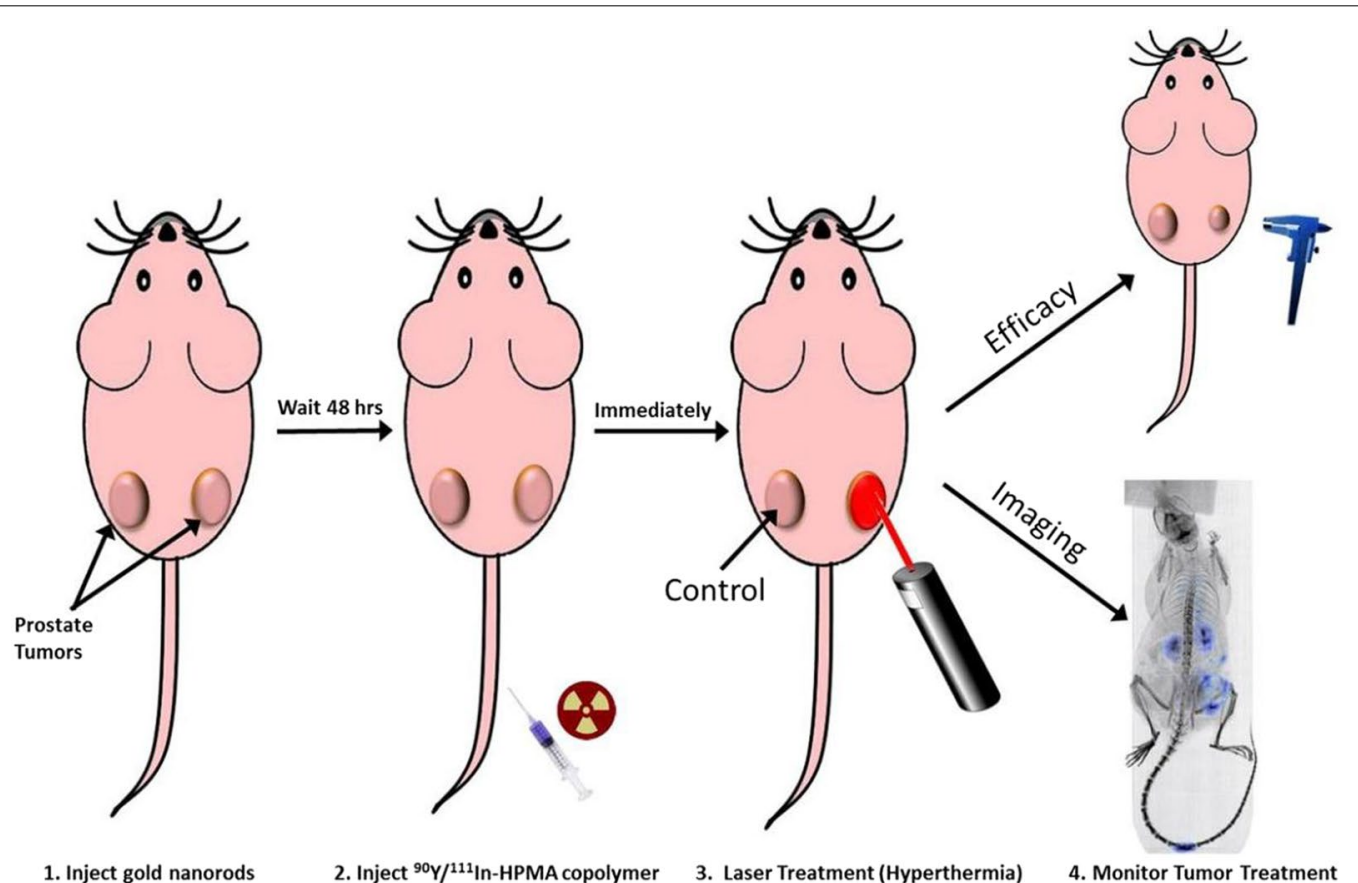

Fig. 11 Methodology of the combination of radiation therapy and hyperthermic treatment for prostate tumor-bearing mice (Reproduced with permission [39]. Copyright 2014, Elsevier Ltd) 
The reports on GNRs as radiosensitizers in radiation therapy discussed above are summarized in Table 2 .

\section{Challenges and prospects}

As a type of high-Z nanostructures, GNRs have attracted much attention in radiation therapy researches owing to their various advantages, including good biocompatibility, good radiation sensitization, unique optical properties, simple synthesis, controllable size and aspect ratio, and easy surface modification. GNRs can also serve as excellent photothermal sensitizers and CT/ PA dual-model contrast agents. Therefore, more and more researches on GNR-based imaging-guided radiation therapy/photothermal therapy have been emerging. Although GNRs have shown great potential in radiation therapy, many problems should be resolved before their clinical application, especially the GNRs-based radiosensitizers with high performance and good bicompatibility should be further developed.

1. GNRs with controllable size and morphology can be prepared using the current methods by adjusting the synthetic conditions, however, detailed and systematic investigations on the effects of experimental parameters and development of better synthesis systems should be conducted, which may make the preparation of GNRs more professional and controllable.

2. The existing methods for CTAB removal/replacement are often complicated and time-consuming, thus, how to improve the treatment process and equipment for seeking a more convenient way should be pay more attention in the future research. At the same time, CTAB on GNRs usually cannot be completely removed by one method, thus, a combination of multiple methods with complementary advantages should be utilized to improve the toxicity reduction effect of GNRs.

3. The radiation sensitization of GNRs is affected by many parameters, including size and surface modification of GNRs, the utilized cell lines, the type of radiation and the radiation dose, thus, in order to construct an optimized composite system based on GNRs for radiation therapy, more researches on GNRs- and radiation- and cell line related parameters for radiation sensitization should be conducted systematically.

4. During clinical application, the accumulation of GNRs in vivo may lead to long-term toxicity, therefore, biocompatible GNRs with a suitable size should be prepared to eliminate or reduce the GNRs accumulation after cancer treatment. GNRs with a size of smaller than $5 \mathrm{~nm}$ demonstrate better penetration into tumor and could be rapidly eliminated via renal system. In addition, the biodistribution, toxicity, and pharmacokinetics of GNRs in radiation therapy should be systematically investigated.

5. Since the radiation dose in radiation therapy should be kept as low as possible to protect patients from risks caused by ionizing radiation, the GNRs-sensitized radiation therapy could be combined with other therapies (e.g. photothermal therapy, photodynamic therapy, and chemotherapy) to reduce the radiation dosage while achieving the maximum therapy efficacy.

Table 2 GNRs as radiosensitizers in radiation therapy

\begin{tabular}{|c|c|c|c|c|}
\hline Nanocomposite & Cell line & Tumor model & $\begin{array}{l}\text { Radiation/radiation } \\
\text { source }\end{array}$ & Refs. \\
\hline GNRs@mSiO $2-R G D$ & MDA-MB-231 & $\begin{array}{l}\text { Orthotopic transplantation nude mice models with human } \\
\text { TNBC }\end{array}$ & X-ray & [53] \\
\hline RGD-GNRs & A375 & / & X-ray & [63] \\
\hline Goserelin-conjugated GNRs & PC3 & Subcutaneous mice models with prostate cancer & X-ray & [64] \\
\hline Goserelin-conjugated GNRs & PC3 & $\begin{array}{l}\text { Swiss nude mice bearing subcutaneous human prostate } \\
\text { cancer }\end{array}$ & X-ray & [65] \\
\hline $\begin{array}{l}\text { RGD- and ACPP coated } \\
\text { core-shell Au@Se nanocom- } \\
\text { posite }\end{array}$ & A375 & Subcutaneous nude mouse models with A375 cancer & X-ray & [66] \\
\hline PEG-coated GNRs & KB & / & X-ray & [67] \\
\hline GNR-SphK1 siRNA & SCC-15; USC HN-1 & Male Balb/C athymic mice bearing USC HN-1 xenografts & Cs-137 gamma ray & [71] \\
\hline AuNR@MS nanostructure & CT-26 cells & / & Co-60 gamma ray & [72] \\
\hline PEG-GNRs & / & Athymic Nu/Nu female mice bearing DU-145 prostate tumor & ${ }^{90} Y$ & [39] \\
\hline $\mathrm{GNRs@SiO}_{2}-\mathrm{FA}$ & HepG2 & / & 125 & [73] \\
\hline
\end{tabular}




\section{Conclusions}

In summary, the research progress regarding the synthesis and toxicity reduction as well as radiation therapy application of GNRs are discussed in this review. GNRs are a type of promising theranostic agents in imagingguided cancer radiation therapy although there are difficulties and great challenges before their clinical application.

\section{Acknowledgements}

This work was supported financially partly by Grants from the National Natural Science Foundation of China (Grant No. 82071975), the Innovation Capacity Support Plan of Shaanxi Province (Grant No. 2018TD002), and the China Postdoctoral Science Foundation (Grant No. 2019T120924).

\section{Authors' contribution}

LX drafted the manuscript. SH and WC designed and revised the manuscript. All authors carried out literature searching and data analysis. All authors have reviewed and approved the final manuscript.

\section{Declarations}

Ethics approval and consent to participate

Not applicable.

\section{Consent for publication}

All authors gave their consent for publication.

\section{Competing interests}

The authors declare that they have no competing interests.

\section{Author details}

'Department of Radiation Oncology, The First Affiliated Hospital, Xi'an Jiaotong University, Xi'an 710061, Shaanxi, China. ${ }^{2}$ Institute of Medical Engineering, School of Basic Medical Sciences, Health Science Center, Xi'an Jiaotong University, Xi'an 710061, Shaanxi, China. ${ }^{3}$ Eye Institute of Xiamen University, Fujian Provincial Key Laboratory of Ophthalmology and Visual Science, School of Medicine, Xiamen University, Xiamen 361102, Fujian, China. ${ }^{4}$ State Key Laboratory of Molecular Vaccinology and Molecular Diagnostics Center for Molecular Imaging and Translational Medicine, School of Public Health, Xiamen University, Xiamen 361102, Fujian, China.

Received: 18 August 2021 Accepted: 14 December 2021 Published online: 28 December 2021

\section{References}

1. Baskar R, Itahana K. Radiation therapy and cancer control in developing countries: can we save more lives? Int J Med Sci. 2017;14(1):13-7.

2. Danhier F, Feron $\mathrm{O}$, Preat $\mathrm{V}$. To exploit the tumor microenvironment: passive and active tumor targeting of nanocarriers for anti-cancer drug delivery. J Control Release. 2010;148(2):135-46.

3. Bertrand N, Wu J, Xu XY, Kamaly N, Farokhzad OC. Cancer nanotechnology: the impact of passive and active targeting in the era of modern cancer biology. Adv Drug Deliv Rev. 2014;66:2-25.

4. Kunz-Schughart LA, Dubrovska A, Peitzsch C, Ewe A, Aigner A, Schellenburg S, Muders MH, Hampel S, Cirillo G, lemma F, Tietze R, Alexiou C, Stephan H, Zarschler K, Vittorio O, Kavallaris M, Parak WJ, Madler L, Pokhrel S. Nanoparticles for radiooncology: mission, vision, challenges. Biomaterials. 2017;120:155-84.

5. Retif P, Pinel $S$, Toussaint M, Frochot $C$, Chouikrat R, Bastogne T, BarberiHeyob M. Nanoparticles for radiation therapy enhancement: the key parameters. Theranostics. 2015;5(9):1030-45.

6. Cui L, Her S, Borst GR, Bristow RG, Jaffray DA, Allen C. Radiosensitization by gold nanoparticles: will they ever make it to the clinic. Radiother Oncol. 2017;124(3):344-56.
7. Her S, Jaffray DA, Allen C. Gold nanoparticles for applications in cancer radiotherapy: mechanisms and recent advancements. Adv Drug Deliv Rev. 2017:109:84-101.

8. Haine AT, Niidome T. Gold nanorods as nanodevices for bioimaging, photothermal therapeutics, and drug delivery. Chem Pharm Bull. 2017;65(7):625-8

9. Marangoni VS, Cancino-Bernardi J, Zucolotto V. Synthesis, physico-chemical properties, and biomedical applications of gold nanorods - a review. J Biomed Nanotechnol. 2016;12(6):1136-58.

10. Liu W, Zhu Z, Deng K, Li Z, Zhou Y, Qiu H, Gao Y, Che S, Tang Z. Gold nanorod@chiral mesoporous silica core-shell nanoparticles with unique optical properties. J Am Chem Soc. 2013;135(26):9659-64.

11. Aioub M, Panikkanvalappil SR, El-Sayed MA. Platinum-coated gold nanorods: efficient reactive oxygen scavengers that prevent oxidative damage toward healthy, untreated cells during plasmonic photothermal therapy. ACS Nano. 2017;11(1):579-86.

12. $X u$ W, Lin $Q$, Yin $Y, X u$ D, Huang $X, X u B$, Wang $G$. A review on cancer therapy based on the photothermal effect of gold nanorod. Curr Pharm Design. 2019;25(46):4836-47.

13. Xia L, Zhang C, Li M, Wang K, Wang Y, Xu P, Hu Y. Nitroxide-radicalsmodified gold nanorods for in vivo CT/MRI-guided photothermal cancer therapy. Int J Nanomed. 2018;13:7123-34.

14. Wang J, Han J, Zhu C, Han N, Xi J, Fan L, Guo R. Gold nanorods/ polypyrrole/m- $\mathrm{SiO}_{2}$ core/shell hybrids as drug nanocarriers for efficient chemo-photothermal therapy. Langmuir. 2018;34(48):14661-9.

15. Chen Y, Bian X, Aliru M, Deorukhkar AA, Ekpenyong O, Liang S, John J, Ma J, Gao X, Schwartz J, Singh P, Ye YQ, Krishnan S, Xie H. Hypoxiatargeted gold nanorods for cancer photothermal therapy. Oncotarget. 2018:9(41):26556-71.

16. Zhou Z, Zhao J, Di Z, Liu B, Li Z,Wu X, Li L. Core-shell gold nanorod@ mesoporous-MOF heterostructures for combinational phototherapy. Nanoscale. 2020;13(1):131-7.

17. Yao Y, Zhang N, Liu X, Dai Q, Liu H, Wei Z, Tie S, Li Y, Fan H, Lan S. A novel fast photothermal therapy using hot spots of gold nanorods for malignant melanoma cells. Nanomaterials. 2018;8(11):880.

18. Chen YS, Zhao Y, Yoon SJ, Gambhir SS, Emelianov S. Miniature gold nanorods for photoacoustic molecular imaging in the second nearinfrared optical window. Nat Nanotechnol. 2019;14(5):465-72.

19. Huang P, Bao L, Zhang C, Lin J, Luo T, Yang D, He M, Li Z, Gao G, Gao B, Fu S, Cui DX. Folic acid-conjugated silica-modified gold nanorods for X-ray/ CT imaging-guided dual-mode radiation and photo-thermal therapy. Biomaterials. 2011:32(36):9796-809.

20. Brown KR, Walter DG, Natan MJ. Seeding of colloidal Au nanoparticle solutions. 2. Improved control of particle size and shape. Chem Mater. 2000;12(2):306-13.

21. Hinman JG, Stork AJ, Varnell JA, Gewirth AA, Murphy CJ. Seed mediated growth of gold nanorods: towards nanorod matryoshkas. Faraday Discuss. 2016;191:9-33.

22. Jana NR, Gearheart L, Murphy CJ. Seed-mediated growth approach for shape-controlled synthesis of spheroidal and rod-like gold nanoparticles using a surfactant template. Adv Mater. 2001;13(18):1389-93.

23. Nikoobakht B, El-Sayed MA. Preparation and growth mechanism of gold nanorods (NRs) using seed-mediated growth method. Chem Mater. 2003;15(10):1957-62.

24. Cheng J, Ge L, Xiong B, He Y. Investigation of pH effect on gold nanorod synthesis. J Chin Chem Soc. 2011;58(6):822-7.

25. Smith DK, Korgel BA. The importance of the CTAB surfactant on the colloidal seed-mediated synthesis of gold nanorods. Langmuir. 2008;24(3):644-9.

26. Ali MR, Snyder B, El-Sayed MA. Synthesis and optical properties of small Au nanorods using a seedless growth technique. Langmuir. 2012;28(25):9807-15.

27. Yan C, Wang Y, Tian Q, Wu H, Yang S. Concentration effect on large scale synthesis of high quality small gold nanorods and their potential role in cancer theranostics. Mater Sci Eng C-Mater Biol Appl. 2018;87:120-7.

28. Martin CR. Nanomaterials: a membrane-based synthetic approach. Science. 1994;266(5193):1961-6.

29. Vigderman L, Khanal BP, Zubarev ER. Functional gold nanorods: synthesis, self-assembly, and sensing applications. Adv Mater. 2012;24(36):4811-41. 
30. Dickson W, Evans PR, Wurtz GA, Hendren W, Atkinson R, Pollard RJ, Zayats AV. Towards nonlinear plasmonic devices based on metallic nanorods. J Microsc. 2008:229(3):415-20.

31. Gao CB, Zhang Q, Lu ZD, Yin YD. Templated synthesis of metal nanorods in silica nanotubes. J Am Chem Soc. 2011;133(49):19706-9.

32. Kim F, Song $\mathrm{JH}$, Yang P. Photochemical synthesis of gold nanorods. J Am Chem Soc. 2002;124(48):14316-7.

33. Toussi SM, Zanella M, Abdelrasoul GN, Athanassiou A, Pignatelli F. Twofold role of hexadecyltrimethylammonium bromide in photochemical synthesis of gold nanorods. J Photochem Photobiol A-Chem. 2015;311:76-84.

34. Yu YY, Chang SS, Lee CL, Wang CRC. Gold nanorods: electrochemical synthesis and optical properties. J Phys Chem B. 1997;101 (34):6661-4

35. Chang SS, Shih CW, Chen CD, Lai WC, Wang CRC. The shape transition of gold nanorods. Langmuir. 1999;15(3):701-9.

36. Okitsu K, Sharyo K, Nishimura R. One-pot synthesis of gold nanorods by ultrasonic irradiation: the effect of $\mathrm{pH}$ on the shape of the gold nanorods and nanoparticles. Langmuir. 2009;25(14):7786-90.

37. Jia YP, Shi K, Liao JF, Peng JR, Hao Y, Qu Y, Chen LJ, Liu L, Yuan X, Qian ZY, Wei XW. Effects of cetyltrimethylammonium bromide on the toxicity of gold nanorods both in vitro and in vivo: molecular origin of cytotoxicity and inflammation. Small Methods. 2020:4(3):1900799.

38. Scaletti F, Kim CS, Messori L, Rotello VM. Rapid purification of gold nanorods for biomedical applications. MethodsX. 2014;1:118-23.

39. Buckway B, Frazier N, Gormley AJ, Ray A, Ghandehari H. Gold nanorodmediated hyperthermia enhances the efficacy of HPMA copolymer$90 \mathrm{Y}$ conjugates in treatment of prostate tumors. Nucl Med Biol. 2014;41(3):282-9.

40. Dickerson EB, Dreaden EC, Huang X, El-Sayed IH, Chu H, Pushpanketh S, McDonald JF, El-Sayed MA. Gold nanorod assisted near-infrared plasmonic photothermal therapy (PPTT) of squamous cell carcinoma in mice. Cancer Lett. 2008;269(1):57-66.

41. Garabagiu S, Bratu I. Thiol containing carboxylic acids remove the CTAB surfactant onto the surface of gold nanorods: an FTIR spectroscopic study. Appl Surf Sci. 2013;284:780-3.

42. Su L, Hu S, Zhang L, Wang Z, Gao W, Yuan J, Liu M. A fast and efficient replacement of CTAB with MUA on the surface of gold nanorods assisted by awater-immiscible ionic liquid. Small. 2017;13(11):1602809.

43. Li DD, Zhang M, Xu F, Chen YZ, Chen BF, Chang Y, Zhong HH, Jin HY, Huang YZ. Biomimetic albumin-modified gold nanorods for photothermo-chemotherapy and macrophage polarization modulation. Acta Pharm Sin B. 2018:8(1):74-84

44. Casas J, Venkataramasubramani M, Wang Y, Tang L. Replacement of cetyltrimethylammoniumbromide bilayer on gold nanorod by alkanethiol crosslinker for enhanced plasmon resonance sensitivity. Biosens Bioelectron. 2013:49:525-30

45. Lee Y, Jang J, Yoon J, Choi J-W, Choi I, Kang T. Phase transfer-driven rapid and complete ligand exchange for molecular assembly of phospholipid bilayers on aqueous gold nanocrystals. Chem Commun. 2019:55(22):3195-8.

46. Huang $P, L i Z M$, Lin J, Cui DX. Preparation of Surface dendrimer-modified gold nanorods by Round-Trip Phase Transfer Ligand Exchange. J Phys Conf Ser. 2009;188:012031.

47. Liu X, Huang N, Li H, Wang H, Jin Q, Ji J. Multidentate polyethylene glycol modified gold nanorods for in vivo near-infrared photothermal cancer therapy. ACS Appl Mater Interfaces. 2014;6(8):5657-68.

48. Kinnear C, Burnand D, Clift MJD, Kilbinger AFM, Rothen-Rutishauser B, Petri-Fink A. Polyvinyl alcohol as a biocompatible alternative for the passivation of gold nanorods. Angew Chem-Int Edit. 2014;53(46):12613-7.

49. Zhao TT, Shen $X Q$, Li L, Guan ZP, Gao NY, Yuan PY, Yao $S Q, X u$ QH, Xu GQ. Gold nanorods as dual photo-sensitizing and imaging agents for two-photon photodynamic therapy. Nanoscale. 2012;4(24):7712-9.

50. Dai Q, Coutts J, Zou JH, Huo Q. Surface modification of gold nanorods through a place exchange reaction inside an ionic exchange resin. Chem Commun. 2008:(25):2858-60.

51. He J, Unser S, Bruzas I, Cary R, Shi Z, Mehra R, Aron K, Sagle L. The facile removal of $C T A B$ from the surface of gold nanorods. Colloid Surf B-Biointerfaces. 2018;163:140-5.
52. Liu L, Xie HJ, Mu LM, Liu R, Su ZB, Cui YN, Xie Y, Lu WL. Functional chlorin gold nanorods enable to treat breast cancer by photothermal/ photodynamic therapy. Int J Nanomed. 2018;13:8119-35.

53. Zhao N, Yang Z, Li B, Meng J, Shi Z, Li P, Fu S. RGD-conjugated mesoporous silica-encapsulated gold nanorods enhance the sensitization of triple-negative breast cancer to megavoltage radiation therapy. Int J Nanomed. 2016;11:5595-610.

54. Luo L, Sun WJ, Feng YS, Qin RX, Zhang JH, Ding DD, Shi TH, Liu XM, Chen XY, Chen HM. Conjugation of a scintillator complex and gold nanorods for dual modal image-guided photothermal and X-rayinduced photodynamic therapy of tumors. ACS Appl Mater Interfaces. 2020;12(11):12591-9.

55. Zhang ZJ, Wang LM, Wang J, Jiang XM, Li XH, Hu ZJ, Ji YL, Wu XC, Chen CY. Mesoporous silica-coated gold nanorods as a light-mediated multifunctional theranostic platform for cancer treatment. Adv Mater. 2012;24(11):1418-23.

56. Shen S, Tang HY, Zhang XT, Ren JF, Pang ZQ, Wang DG, Gao HL, Qian $Y$, Jiang XG, Yang WL. Targeting mesoporous silica-encapsulated gold nanorods for chemo-photothermal therapy with near-infrared radiation. Biomaterials. 2013;34(12):3150-8.

57. Luo GF, Chen WH, Lei Q, Qiu WX, Liu YX, Cheng YJ, Zhang XZ. A triple-collaborative strategy for high-performance tumor therapy by multifunctional mesoporous silica-coated gold nanorods. Adv Funct Mater. 2016;26(24):4339-50.

58. Shang W, Zeng C, Du Y, Hui H, Liang X, Chi C, Wang K, Wang Z, Tian J. Core-shell gold nanorod@metal-organic framework nanoprobes for multimodality diagnosis of glioma. Adv Mater. 2017;29(3):1604381.

59. Li YT, Jin J, Wang DW, Lv JW, Hou K, Liu YL, Chen CY, Tang ZY. Coordination-responsive drug release inside gold nanorod@metal-organic framework core-shell nanostructures for near-infrared-induced synergistic chemo-photothermal therapy. Nano Res. 2018;11(6):3294-305.

60. Zeng JY, Zhang MK, Peng MY, Gong D, Zhang XZ. Porphyrinic metalorganic frameworks coated gold nanorods as a versatile nanoplatform for combined photodynamic/photothermal/chemotherapy of tumor. Adv Funct Mater. 2018;28(8):1705451.

61. Lusic H, Grinstaff MW. X-ray-computed tomography contrast agents. Chem Rev. 2013;113(3):1641-66.

62. Jelveh S, Chithrani DB. Gold nanostructures as a platform for combinational therapy in future cancer therapeutics. Cancers. 2011;3(1):1081-110.

63. Xu W, Luo T, Li P, Zhou C, Cui D, Pang B, Ren Q, Fu S. RGD-conjugated gold nanorods induce radiosensitization in melanoma cancer cells by downregulating $a(v) \beta_{3}$ expression. Int J Nanomed. 2012;7:915-24.

64. Wolfe T, Chatterjee D, Lee J, Grant JD, Bhattarai S, Tailor R, Goodrich G, Nicolucci P, Krishnan S. Targeted gold nanoparticles enhance sensitization of prostate tumors to megavoltage radiation therapy in vivo. Nanomedicine. 2015:11(5):1277-83.

65. Khoo AM, Cho SH, Reynoso FJ, Aliru M, Aziz K, Bodd M, Yang X, Ahmed MF, Yasar S, Manohar N, Cho J, Tailor R, Thames HD, Krishnan S. Radiosensitization of prostate cancers in vitro and in vivo to erbium-filtered orthovoltage X-rays using actively targeted gold nanoparticles. Sci Rep. 2017:7:18044.

66. Chang Y, He L, Li Z, Zeng L, Song Z, Li P, Chan L, You Y, Yu XF, Chu PK, Chen TF. Designing core-shell gold and selenium nanocomposites for cancer radiochemotherapy. ACS Nano. 2017;11(5):4848-58.

67. Ma N, Wu FG, Zhang X, Jiang YW, Jia HR, Wang HY, Li YH, Liu P, Gu N, Chen Z. Shape-dependent radiosensitization effect of gold nanostructures in cancer radiotherapy: comparison of gold nanoparticles, nanospikes, and nanorods. ACS Appl Mater Interfaces. 2017;9(15):13037-48.

68. Li P, Shi YW, Li BX, Xu WC, Shi ZL, Zhou C, Fu S. Photo-thermal effect enhances the efficiency of radiotherapy using Arg-Gly-Asp peptidesconjugated gold nanorods that target av $\beta 3$ in melanoma cancer cells. J Nanobiotechnol. 2015;13:52.

69. Movahedi MM, Mehdizadeh A, Koosha F, Eslahi N, Mahabadi VP, Ghaznavi $\mathrm{H}$, Shakeri-Zadeh A. Investigating the photo-thermo-radiosensitization effects of folate-conjugated gold nanorods on KB nasopharyngeal carcinoma cells. Photodiagnosis Photodyn Ther. 2018;24:324-31.

70. Sun Q, Wu J, Jin L, Hong L, Wang F, Mao Z, Wu M. Cancer cell membrane-coated gold nanorods for photothermal therapy and radiotherapy on oral squamous cancer. J Mater Chem B. 2020;8(32):7253-63. 
71. Masood R, Roy I, Zu S, Hochstim C, Yong KT, Law WC, Ding H, Sinha UK, Prasad PN. Gold nanorod-sphingosine kinase siRNA nanocomplexes: a novel therapeutic tool for potent radiosensitization of head and neck cancer. Integr Biol. 2012;4(2):132-41.

72. Koosha F, Farsangi ZJ, Samadian H, Amini SM. Mesoporous silica coated gold nanorods: a multifunctional theranostic platform for radiotherapy and X-ray imaging. J Porous Mat. 2021;28(6):1961-8.

73. Gao B, Shen L, He KW, Xiao WH. GNRs@SiO - -FA in combination with radiotherapy induces the apoptosis of $\mathrm{HepG} 2$ cells by modulating the expression of apoptosis-related proteins. Int J Mol Med. 2015;36(5):1282-90.

\section{Publisher's Note}

Springer Nature remains neutral with regard to jurisdictional claims in published maps and institutional affiliations.

- fast, convenient online submission

- thorough peer review by experienced researchers in your field

- rapid publication on acceptance

- support for research data, including large and complex data types

- gold Open Access which fosters wider collaboration and increased citations

- maximum visibility for your research: over $100 \mathrm{M}$ website views per year

At BMC, research is always in progress.

Learn more biomedcentral.com/submissions 